\title{
COGNITIVE ECONOMICS
}

\section{MILES KIMBALL}

University of Michigan

\section{Abstract}

Cognitive economics is the economics of what is in people's minds. It is a vibrant area of research (much of it within behavioural economics, labour economics and the economics of education) that brings into play novel types of data, especially novel types of survey data. Such data highlight the importance of heterogeneity across individuals and highlight thorny issues for welfare economics. A key theme of cognitive economics is finite cognition (often misleadingly called "bounded rationality"), which poses theoretical challenges that call for versatile approaches. Cognitive economics brings a rich toolbox to the task of understanding a complex world.

\section{Introduction}

Names matter. In particular, naming subfields of economics can help economists to see connections they otherwise might not have seen between their own research agenda and the research agenda of other economists. A well-chosen name can foster esprit de corps within a subfield and help in explaining the unifying ideas in that subfield to students. This paper is an argument for the appropriateness of the name "cognitive economics" for a growing subfield of economics, and for the importance of the research that has been done and can be done in cognitive economics. It also discusses key themes in cognitive economics and the issues they raise.

It is important to stress that (if the name I propose is deemed acceptable) research in cognitive economics has already been underway for a long time. However, as a participant in this subfield, it seems to me that research in this area has been growing in recent years. I argue here that there are great opportunities for further research in cognitive economics.

Even the name "cognitive economics" is not altogether new, as performing a web search of "cognitive economics" quickly shows. Notable in using this label are two 2004 edited volumes: Paul Bourgine and Jean-Pierre Nadal's Cognitive Economics: An Interdisciplinary Approach and Massimo Egidi and Salvatore Rizzello's two-volume Cognitive Economics, both of which predate the earliest April 7, 2007 version of this paper by several years. Although their views are not exactly the same as the one I give below, I consider the way they use the term "cognitive economics" as broadly consistent with mine. However, the label "cognitive economics" is still not in broad use. My hope is that this paper will help in popularizing what I think is a very useful label, as well as foster the research that it refers to. 
Below, much of the discussion is about how cognitive economics relates to behavioural economics (primarily as a subset of behavioural economics, although not entirely). However, I also see a logical relationship between cognitive economics and human capital theory. The development of economics in many topical areas often follows a progression from treating a model element as a black box viewed from the outside to peering into the mechanism inside the black box. In black box treatments, the cognitive and informational nature of human capital and technology is pushed into the background. For human capital and technology, looking deeply into the black box involves looking at what is going on inside human minds. Thus, I see cognitive economics as a logical extension and broadening of human capital theory, including both those types of human capital that are acquired and those types that one is born with.

\section{Defining cognitive economics}

Cognitive economics is defined as the economics of what is in people's minds. In practical terms, this means that cognitive economics is characterized by its use of a distinctive kind of data. This includes data on expectations, hypothetical choices, cognitive ability and expressed attitudes. Categorizing a field of economics by the type of data used and theorized about makes some sense from a practical point of view because working with a particular type of data often requires some specific human capital. A simple typology of areas of economic research by type of data addressed would be something like the following. (Note that each of these areas of economics is concerned with data on naturally occurring market choices and time allocations as well as its distinctive type of data.)

- Traditional economics: data on naturally occurring market choices and time allocations only

- Experimental economics: data on choices in artificial situations with real stakes

- $\quad$ Field experiments

- $\quad$ Laboratory experiments

- $\quad$ Neuroeconomics: data from brain imaging and other ways of measuring brain activity, data on eyeball orientation and data on other physiological measures, such as skin conductance, muscle activation or hormone levels

- Genoeconomics: data on genes

- Cognitive economics: data on hypothetical choices, psychometric data, and selfreport data on mental contents

- $\quad$ Survey measures of expectations

- $\quad$ Survey measures of preference parameters

- $\quad$ Direct measures of intelligence

- $\quad$ Direct measures of decision-making skill

- $\quad$ Self-reported emotions, including self-reported happiness

- $\quad$ Survey measures of beliefs about how the world works. 
There is some tension between the definition of cognitive economics as the economics of what is in people's minds and the practical delineation of cognitive economics as the use of survey data to access what is in people's minds in relation to economics. In particular, experimental data and neuroeconomic data are also key ways of getting at what is in people's minds. To the extent only or mainly experimental data and neuroeconomic data are used, those labels will serve just fine. However, I would class mixed approaches using a heavy dose of survey data combined with some experimental data or some neuroeconomics data as cognitive economics. As ways are found to reduce the cost of experimental data and neuroeconomic data, such mixed approaches to cognitive economics will become more and more important.

The name "cognitive economics" is coined by analogy to "cognitive psychology", the area of psychology that examines internal mental processes such as problem solving, memory and language. Historically, cognitive psychology was a departure from the behaviourism of Ivan Pavlov, Leonard Bloomfield and B. F Skinner, which insisted that only outward behaviour was a legitimate subject of study. Similarly, cognitive economics is a departure from the tradition in economics that only outward behaviour is a fit subject of study for economics: a tradition that was fostered by Vilfredo Pareto, Paul Samuelson and Milton Friedman (1912-2006), among others, and was still strong when I attended graduate school in the mid-1980s. ${ }^{1}$

The name "cognitive economics" might initially sound as if it is yet another synonym for behavioural economics (which might have been better named psychological economics). However, although there will be overlap, I mean something different. The most obvious difference is that cognitive economics is narrower. Behavioural economics addresses a huge range of issues and cuts across all of the data types listed above, while cognitive economics focuses primarily on innovative kinds of survey data, along with laboratory data of the same basic type. To say the same thing in a more pointed way, behavioural economics is so big, it is very difficult to keep up with all of the developments within behavioural economics. Cognitive economics has a more manageable size.

Second, important pieces of cognitive economics are inspired by the internal dynamic of economics rather than by psychology. As examples, in addition to the interest in intelligence measures that arose out of human capital theory, the importance of expectations and preference parameters in macroeconomics has spurred a desire for direct measurement of expectations and preference parameters.

Third, I think it is fair to say that behavioural economics has been to an important degree a school of thought as well as an area of study. In coming up with a definition of cognitive economics, I want to indicate an area of study, not a particular viewpoint. To make this point clear, a research agenda arguing that, in fact, data on mental contents and hypothetical choices was unreliable would be part of cognitive economics. Indeed, at the more constructive end of doubting data on mental contents and psychological data, in my view it is hard to take empirical work on data on mental contents or hypothetical choices seriously

\footnotetext{
${ }^{1}$ For this history, see the discussion in Franz Dietrich and Christian List (2012).
} 
unless the statistical modelling includes a response error term. Kimball et al. (2008) give a basic example of such modelling. Moreover, when studying more than one type of question within a survey wave, it is typically important to allow also for correlations across different response errors within a survey wave.

Finally, there is a slice of behavioural economics that explicitly excludes the mind: notably the "mindless economics" that Faruk Gul and Wolfgang Pesendorfer (2008) advocate, in which empirical data suggesting nonstandard outward behaviour is studied from a purely axiomatic point of view. (There is a fair amount of microeconomic theory done in a way consistent with this view, although often by economists who themselves are also comfortable with a more mindful approach.)

In addition to the overlap between cognitive economics and behavioural economics, there is an obvious complementarity between cognitive economics and behavioural economics.

Although it is possible to consider nonstandard theories of human behaviour on the basis of standard data on market decisions alone, freeing up economic theory from traditional assumptions tends to increase the number of free parameters. There is a great value to additional data that can help pin down these additional free parameters. Standard data on market decisions do not always provide power for decisive tests of new theories. Looking at the complementarity from the other direction, even an approach to new kinds of data that begins by attempting to measure standard economic concepts such as expectations and preferences with the hope that these concepts obey the standard assumptions is likely to find at least some areas where the standard assumptions seem to be violated. Here, behavioural (psychological) economics can help provide alternative theories to be tested.

Before moving on, let me make the practical delineation of cognitive economics by its heavy use of novel types of survey data more vivid by giving a few specific examples.

1. Intelligence tests are used in one way when intelligence tests are seen as one input into earning ability. However, quiz questions can also be used to see if people understand what they would need to understand to make economic decisions in the way specified in standard economic models. The University of Michigan's Cognitive Economics Survey and RAND's American Life Panel both have extensive batteries of questions measuring financial sophistication, and many other surveys have basic financial literacy questions. Analysing such data can be very sobering for economists used to assuming very high levels of competence on the part of the agents in their models.

2. Survey measurement of expectations at the individual level has a long and distinguished history. For example, many macroeconomists, including many macroeconomists in central banks, take survey measures of inflation expectations seriously. The University of Michigan's Survey of Consumers, the University of Michigan's Health and Retirement Study and RAND's American Life Panel have many other types of expectations data: for example, personal mortality expectations and stock market return expectations. Techniques for dealing with expectations data have become quite sophisticated. See, for example, Jeffrey Dominitz and Charles Manski (2011) and Hudomiet et al. (2011). 
3. If one is willing to give some credence to hypothetical choices, it is possible to design survey measures of a wide range of preference parameters. The University of Michigan's Health and Retirement Study has hypothetical choice measures of risk aversion, time preference and intertemporal substitution, the income elasticity of labour supply, and altruism. However, in principle, almost any type of preference parameter can be assessed by hypothetical choice questions. Internal consistency checks (including estimation of the size of response error variance) can often be devised to help identify the practical boundary of what can be measured at this point in the development of technique. (For example, it turns out that measuring the marginal propensity to consume is very difficult. The approach pioneered by Matthew Shapiro and Joel Slemrod and continued with Claudia Sahm had to make many compromises. See Shapiro and Slemrod (2003) and Sahm et al. (2012).)

4. There is now a vast literature in economics using self-reported happiness or other subjective well-being measures such as life satisfaction, or one's rank on a ladder of life. The recent push to develop national well-being measures, and doubts about the comprehensiveness of any one survey question on well-being, have led to a more and more multidimensional approach to measuring subjective wellbeing. That in turn has led to efforts to combine the measurement of a vector of levels of subjective well-being with hypothetical choice data on how individuals would trade off different dimensions of well-being. See Benjamin et al. (2014b).

5. Data on the personality psychologists' big five personality traits (openness to experience, conscientiousness, extraversion, agreeableness and neuroticism) are available on many surveys. (For example, the University of Michigan's Health and Retirement Study has questions to assess the big five on its psychosocial leave-behind: a pencil and paper survey left behind after in-person interviews.) However, other traits may be just as important. Almlund et al. (2011) give a useful survey of some of the results that have been found.

Having defined the field of cognitive economics in what is hopefully a fairly neutral way, let me give my opinion on existing research and future directions in cognitive economics, organized around three themes: using data on hypothetical choices and mental contents: (i) to identify individual heterogeneity; (ii) to revisit welfare economics; and (iii) to study finite cognition. Data on hypothetical choices and what is in people's minds has obvious relevance to these three themes. Finite cognition also raises some important theoretical issues that I will discuss.

\section{Identifying individual heterogeneity}

Heterogeneity across individuals in preferences and cognitive ability is not at all controversial. However, data limitations have often forced economists to assume uniformity. Here the kind of data discussed above can do a lot to allow economists to capture some of the heterogeneity that exists. In addition to mattering in obvious ways for empirical work, direct data on preference heterogeneity across individuals can inspire theory with a greater emphasis on heterogeneity. For example, Kimball et al. (2015b) use estimates of the 
distribution of risk tolerance from hypothetical choice data in the Health and Retirement

Study to calibrate a model of "portfolio rebalancing in general equilibrium".

\section{Revisiting welfare economics}

Concern with policy and overall welfare motivates some of the concern with measuring preference parameters that I discussed above in the context of identifying individual heterogeneity. In particular, the population distributions of the elasticity of intertemporal substitution, labour supply elasticities and interpersonal dependencies in preferences have important implications for the welfare effects of capital and labour taxation. In addition to data on preferences based on hypothetical choices, there has been considerable interest in using data on self-reported happiness to study welfare issues.

The use of self-reported happiness to study welfare issues illustrates a key methodological issue in cognitive economics. Whenever a new measure is used, its relationship to standard concepts of economic theory is at issue. For example, welfare economics is based on preferences, with the objective of getting people as much as possible of what they want. Thus, in order to use self-reported happiness to address welfare issues, it is crucial to establish the relationship between self-reported happiness and preferences. The most common assumption in the economics literature using self-reported happiness has been that self-reported happiness is equal to some version of utility. If self-reported happiness were, in fact, tightly linked to preferences in this way, that would be of enormous importance for welfare economics. ${ }^{2}$ Kimball and Willis (2006) argue at length that self-reported happiness does not behave like utility, but has a more complex relationship to utility. Benjamin et al. (2012, 2014a, 2014b) back up this view.

It is possible, however, that happiness data could have a tight relationship to preferences even if the level of happiness does not. In particular, to explain the data, Kimball and Willis (2006) suggest that a large component of self-reported happiness depends on recent innovations in lifetime utility. Whenever people receive good news about lifetime utility, self-reported happiness temporarily spikes; whenever people receive bad news about lifetime utility, self-reported happiness temporarily dips. If true, this means that while it is questionable to use the level of happiness to infer preferences, the dynamics of happiness are informative about preferences and so can be used to inform welfare economics. Like the empirically doubtful assumption that the level of happiness has a tight relationship to utility, a tight relationship between the impulse response of happiness to news and the size of innovations to lifetime utility would have great practical value for economists in areas where market choices are not fully informative about preferences. Even if such an assumption is only approximately true, it would mean that the dynamics of happiness could be used to study interpersonal dependencies in the utility function, preferences over events largely outside of one's control, such as the death of one's spouse, and preferences over

\footnotetext{
${ }^{2}$ Layard (2005) explicitly makes some of the policy recommendations that would flow from assuming that self-reported happiness directly indicates true preferences. It is sometimes hard to distinguish the view that self-reported happiness is equal to a version of utility in the economist's sense of utility from a view common among psychologists studying happiness (following Kahneman, 1999) that self-reported happiness is distinct from preferences, but that as a matter of public policy we should maximize the present discounted value of self-reported happiness rather than give people what they prefer.
} 
nonfinancial aspects of public policy. Work on this hypothesis is still in its infancy. Kimball et al. (2006) and Kimball et al. (2015a) are examples of work in this area. (Here it is important to distinguish between focusing on the short-run dynamics of happiness as informative and studying the long-run changes once the dynamics have settled down, as in, say, Ishino et al. (2012).)

\section{Studying finite cognition}

Taking a simplified view of information as recorded data and data summaries, for the purposes of this paper I will call all of the other operations of the human mind besides the bare recording and accessing of information "cognition", without the finer distinctions that psychologists often focus on. Moreover, to avoid the judgment Herbert Simon's phrase "bounded rationality" can inadvertently suggest, I will refer instead to "finite cognition". 3 Finite cognition means something more than just imperfect information: it means finite intelligence, imperfect information processing, and decision-making that is costly. Finite cognition is the third key theme I see for cognitive economics.

If true, explanations based on finite cognition have enormous practical consequences and policy implications. In particular, finite cognition implies that even in the absence of externalities, welfare can often be improved by economic education, setting up appropriate default choices for people, or providing disinterested, credible advice. By contrast, explanations of puzzling behaviour on the basis of individuals maximizing exotic preferences imply (if true) that welfare improvements must come in the standard way from addressing externalities, or in the case of inconsistent preferences, by taking sides in an internal conflict. Once puzzling behaviour that is difficult to explain on the basis of standard economic theory is identified, it is hard to think of a more important question than whether people behave that way because they want to, or simply because they are confused.

My perspective on finite cognition is close to that of the excellent discussion by Conlisk (1996). I will limit myself to highlighting a few of what I consider the most salient points, with my own spin.

\subsection{The reality of finite and scarce cognition}

The first key point is the reality of finite cognition. Although the inadequacies of our current tools can make it hard to study finite cognition theoretically, the claim that human intelligence is finite and that finite intelligence matters for economic life (scarce cognition) is not really controversial. ${ }^{4}$ Even those economists whose opinion of their own intelligence

\footnotetext{
${ }^{3}$ Often, the inadvertent judgment suggested by "bounded rationality" is quite inappropriate. For example, if decision-making is actually costly, which is more "rational", to choose in a way that takes into account the costliness of decision-making or to pretend that decision-making has zero cost? If one's intelligence is actually finite, which is more rational, taking into account the limits on one's intelligence, or pretending that one's thinking power is unlimited? There is certainly a sense in which knowing and adjusting to one's own limitations can often be the height of "rationality".

${ }^{4}$ There are many problems that are too hard for even those with very high levels of intelligence. For example, one of the problems with Bayesian updating is that, strictly speaking, it involves putting a positive probability on a much greater than astronomically huge set of possibilities. Various strategies of economizing on information processing are always essential in practice. Even the existence of a utility function itself is, in a sense, a technique of economizing on information transfer and processing. If evolution could process an infinite amount of information, and the genetic code could transmit an infinite amount of information, we could be endowed with decision rules embracing essentially all contingencies instead of mere objective functions and calculation capabilities.
} 
is unreasonably exalted are regularly reminded by what they see in students and coworkers that not everyone has unlimited intelligence. Many people pay substantial sums for financial advice even aside from commissions on transactions. Even those who have low wage rates, so that their time is less expensive, often pay others to do their tax returns. As for lawyers, even if one considers talking in a courtroom a special skill that is not just a matter of intelligence, people pay a lot of money to lawyers who merely read law books and extract the relevant information. If everyone had infinite intelligence, it would be easy to understand the law books on one's own, and paying someone else to do it would only make sense if one's wage rate was higher than the lawyer's wage rate, or if one was a slow reader for physiological reasons. If everyone had infinite intelligence, even finite reading speeds would not give trained lawyers enough of an edge for them to charge the fees they do.

One of the most important economic manifestations of finite intelligence is the expensive and time-consuming acquisition of human capital. Most obviously, the large amount of resources devoted to mathematical education and research would make little economic sense in a world in which everyone had infinite cognition. Mathematicians spend their entire careers discovering and teaching things with very little informational content about the external world: things that would be easily deducible by anyone with infinite intelligence. In other subject areas, education may involve a significant amount of straightforward information transfer. However, in most areas, the acquisition of useful habits of thought is at least as important. ${ }^{5}$ Teaching students to "think like an economist" is itself somewhere between information transfer and the inculcation of some of those useful habits of thought. Below I present a model of the effects of being taught a standard model of portfolio choice. This is an area where I think many individuals are confused and where making the right choices is important. This model of misunderstanding is relatively simple, but breaks some of the normal theoretical taboos. The remainder of this section makes the case for why it is sometimes necessary to break those taboos.

\subsection{Difficulties in studying finite cognition with standard theoretical tools}

One key reason it is not easy using our standard theoretical tools to model finite cognition is the "infinite regress" problem emphasized by John Conlisk (1996). The infinite regress problem afflicts models that assume a cost of computation or other decision-making cost. The problem is that figuring out how much time to spend in making a decision is almost always a strictly harder decision than the original decision. In particular, one would typically need to know the right choice to the original decision to calculate the value of making additional computations to make the right choice instead of another choice. Given costly decision-making, the agent faces a serious issue of figuring out whether it is worth thinking carefully about the original problem, which leads to the issue of figuring out whether it is worth thinking carefully about thinking carefully about the original problem, and so on.

\footnotetext{
5 This becomes clear when one thinks of what education that was straightforward Bayesian updating of information would look like. After diligent information acquisition in elementary and secondary school, students would arrive at college with a mental checklist of blanks to be filled in as "true" or "false" and parameter values (including probabilities) to be adjusted according to each new piece of data encountered. Education as straightforward Bayesian updating would not involve any true insights: only partial confirmations and discontinuations of things students saw as at least dim possibilities from the very beginning.
} 
Costs to decision-making are a natural enough assumption for economists that a substantial percentage of all applied economic theory papers might include them, if it were not for the infinite regress problem. Finessing the infinite regress problem somehow is essential if economists are to develop effective theoretical tools for studying finite cognition. There are several feasible strategies for getting around the infinite regress problem: every one of which requires breaking at least one inhibition shared by many economists. Least transgressive are models in which an agent sits down once in a long while to think very carefully about how carefully to think about decisions of a frequently encountered type. For example, it is not impossible that someone might spend one afternoon considering how much time to spend on each of many grocery-shopping trips in comparison shopping. In this type of modelling, the infrequent computations of how carefully to think about repeated types of decisions could be approximated as if there were no computational cost, even though the context of the problem implies that those computational costs are strictly positive.

A second strategy is to give up on modelling finite cognition directly and use models of limited information transmission capacity as a way of getting agents to make more imperfect decisions. In other words, one can accept the fact that our standard tools require constrained optimization with its implication of infinite intelligence somewhere in the model, but handicap agents in the model by giving them a "thick skull" that is very inefficient at transmitting information to the infinitely intelligent decision-maker within (i.e. the perfect constrained optimizer within). This is a way to interpret the program of Christopher Sims (2002) that disconnects the implied transmission bit-rates from anything in the external world because low bit-rates would only be a metaphor for finite cognition. ${ }^{6}$

A third feasible strategy is in the spirit of what the complexity theorists call "agent-based modelling". ${ }^{7}$ This typically involves modelling agents with very limited intelligence, such as finite-state automata. One of the findings is that such very limited agents can still handle some kinds of decisions surprisingly well. Many other modelling techniques such as adaptive expectations or simple rules of thumb similarly endow the agents in models with unrealistically subhuman intelligence. This type of modelling substitutes the problem of agents that have unrealistically subhuman intelligence for the problem we have been focusing on of agents that have unrealistically superhuman intelligence. Despite this lack of realism, the results can be very instructive because the failure of realism is in the opposite direction from what economists are used to.

In this paper, I would like to focus on a fourth strategy for getting around the infinite regress problem, one that seems to me less commonly used: modelling economic actors as doing constrained optimization in relation to a simpler economic model than the model treated as true in the analysis. This simpler economic model treated as true by the agent can be called a "folk theory". 8

\footnotetext{
${ }^{6}$ Sticky information of various sorts has become an important topic area in macroeconomics. Michael Woodford (2002) follows the Sims approach directly. A substantial literature stimulated by Greg Mankiw and Ricardo Reis (2002) models sticky information as agents who only periodically incorporate new external information into their inner information sets.

${ }_{8}^{7}$ Agent-based modelling is a big emphasis of Bourgine and Nadal (2004). See also the review by Wilcox (2005a).

8 Although the relevant chapters do not treat subjective views as formal folk theories, the theme of subjectivity is important in the Austrian and Hayekian economics emphasized in Egidi and Rizzello (2004), a pair of edited volumes with the title Cognitive
} 
A folk theory should not be confused with the folk theorem of repeated game theory. We are talking about folk economics in the same sense as the well established ideas of "folk psychology", "folk physics" and "folk biology" (all of which are worth looking up on Wikipedia).

My example of a folk theory model will be a partially uninformed household that solves a portfolio choice problem as if the objective function were additively separable in the outcomes for the various securities making up the portfolio. The justification for such a modelling approach is the idea that it is possible for economic actors to be aware of a simple economic theory, but unaware of more sophisticated economics. This lack of awareness makes them act in their own eyes as if the simpler theory were true.

\subsection{Modelling unawareness requires a subjective state space for the economic actor distinct from the true state space $^{9}$}

The idea of someone being unaware of an idea, while intuitive, has more radical theoretical implications than one might at first suspect. These implications are encapsulated in the title of an important paper by Dekel et al. (1998): "Standard State-Space Models Preclude Unawareness". ${ }^{10}$ Dekel et al. (1998, p. 164) say the following about two "properties of knowledge [that] are usually assumed, but will prove problematic for an agent who is unaware of something":

Necessitation is the assumption that the agent "knows all tautologies." This name comes from the philosophy literature. Monotonicity says that if $E$ implies $F$, then knowledge of $E$ implies knowledge of $F$.

The reader should suspect that there will be problems with making these assumptions hold in a model where the agent is unaware of some possibilities. Both seem to require the agent to have a certain understanding of the state space which seems questionable when the agent is unaware of something.

Later on, Dekel et al. (1998, p. 170) argue for relaxing what they call the "real states" assumption as follows:

\footnotetext{
Economics. The work of Karl Polanyi, with its emphasis on tacit knowledge, is also highlighted. A folk theory can be tacit, rather than fully expressed by agents in words. See also the review by Wilcox (2005b).

${ }^{9}$ The proof of this statement in Dekel et al. (1998) involves assuming event sufficiency (the very useful assumption that if two propositions are true on the same subset of a state space, the agent is aware of one if and only if he or she is aware of the other), plausibility (unawareness implies not knowing and not knowing that one doesn't know), KU introspection (one never knows one is unaware of a particular event), AU introspection (being aware of the possibility of being unaware of a specific event implies being aware of the possibility of that event) and weak necessitation (being aware of a proposition implies being aware of "obvious" tautologies involving that proposition, such as the statement that the proposition implies itself).

${ }^{10} \mathrm{My}$ attempt to translate the formal mathematical argument for why "standard state space models preclude unawareness" into words (although admittedly not into normal English) goes as follows. Because of the fundamental meaning of "unawareness", for any event, it is a contradiction to know that you are unaware of that event, because that knowledge of unawareness would make you aware of the possibility of the event. If you know the state space (as several different tempting assumptions imply you would), you know the things that are always true in the state space, including this basic logic. That is, you know that you will never know that you are unaware of a particular event. However, knowing that you don't know something implies that you are aware of the possibility of that thing. In particular, knowing that you will never know that you are unaware of a particular event means you must be aware of the possibility of being unaware of that particular event, but being aware of the possibility of being unaware of something implies that you are aware of that thing. In particular, being aware of the possibility of being unaware of a particular event implies that you must be aware of the possibility of that particular event. Because this argument works for any event, if you know the state space, you must be aware of the possibility of every event in that state space.
} 
In standard state-space models, states play two distinct roles: they are the analyst's descriptions of ways the world might be and they are also the agent's descriptions of ways the world might be. If the agent is unaware of some possibility, though, 'his' states should be less complete than the analyst's. In particular, the propositions the agent is unaware of should not 'appear in' the states he perceives.

This description of the real states assumption is very close to what the stricture of "rational expectations" has meant in practice within macroeconomics: whatever model the analyst is using, the agent also has that model in his or her mind. ${ }^{11}$ Departures from the real states assumption would allow agents to have a different model of the economic situation in their minds than the maintained assumptions the analyst is using to model the situation of those very agents. ${ }^{12}$ For example, the agents might have in mind an outdated model of the economic situation that appeared in a highly respected economics article from years gone by, while the analyst takes a more sophisticated model as the maintained assumption. In this case, to say that it is ridiculous for the agents to have in mind an outdated economic model would be to claim that it was unreasonable for anyone, esteemed predecessor or not, to ever have entertained the outdated model.

For example, think of a high school senior deciding whether or not to go to college. ${ }^{13}$ Suppose going to college will reduce computation costs that aid in future economic decision-making. Full-scale calculation of the value of this reduction in economic decisionmaking costs would involve knowing what the optimal decisions are for many choices in the future, as well as the likely faulty decisions given higher decision-making costs. However, the high school senior need not be modelled as approaching this problem as a full-scale Bayesian optimizer. Instead, the high-school senior might be modelled as having in mind a simple black-box model of human capital similar to Becker's original human capital model, with some very rough expectations about what the value of the benefits of education are. ${ }^{14}$

Note that if someone is successfully taught a more sophisticated model, this would involve an expansion in the individual's subjective state space. If positive probabilities were accorded to the newly added states, this must necessarily involve a departure from Bayesian updating.

Presumably it is also possible for people to "see the light" even without being explicitly taught. For example, the agent might be driven to entertain an expanded model if the probability of observed events conditional on the initial folk model ever appeared sufficiently low. ${ }^{15}$ We all recognize the practical importance of expansions in one's

\footnotetext{
${ }^{11}$ For perspective on expectations, it is useful to read early discussions of expectations in economics, such as Shackle (1949).

${ }^{12}$ Because the economic theorist would then know more about the fundamental situation than the agent the theorist is modelling, a departure from the real states assumption could be in the opposite direction from the common econometric assumption that the agents know more than the econometrician. Of course, both gaps can occur: the analyst could know more of the basic structure of the situation, while the agent knows certain parameters better.

${ }^{13}$ Finite cognition is an unavoidable issue when making decisions about one's own education. See Kimball (2013) and Kimball and Smith (2013).

${ }^{14}$ One practical implication for economists of such a failure of full-scale rational expectations is that expectations must be measured rather than deduced. Given the fact that the high school senior cannot really calculate the true value of the benefits of education, there is no reason to assume that these expectations will be tightly anchored to the true value, so empirical implementation of such a model should ideally include an attempt to directly measure the expectations of high school seniors.
} 
subjective state space when in scientific contexts we say "Asking the right question is half the battle".

\subsection{Using folk theories to model finite cognition: A portfolio choice example}

Ultimately, the choice among folk theories in a folk theory model must be based on direct evidence about how people view the world. However, to design questions to determine how people view the relevant aspects of the world, it is important to develop formal candidate folk theories, just as it is important to develop the theories that we as analysts treat as our best approximation to the truth.

The definition of a folk theory in this context is simply any theory that one or more agents in the model hold, other than the theory the analyst is taking as the maintained hypothesis. Clearly, the desirable properties for a modelled folk theory are quite different from the desirable properties for a theory proposed as a good approximation of reality. A folk theory need not be logically consistent at a deep level. Indeed, in representing reality, it may be a positive virtue for a folk theory to have logical inconsistencies of a form similar to the logical inconsistencies real people might have in their views of the world. Other than (a) descriptive accuracy as a reasonable representation of how people actually view the world, for theoretical purposes the key desirable properties for a modelled folk theory are (b) providing a clear prediction for how the people holding that folk theory will behave in various circumstances and (c) representing clearly what the people holding the folk theory are confused about and what they do understand. In terms discussed in Richard Herrnstein (1997), particular in the chapters with Drazen Prelec, a folk theory should at least implicitly model the accounting framework that an agent uses, in addition to the objective function.

Because it need not be logically consistent at a deep level, the argument for a folk theory can involve (correct reasoning about) logical leaps and plausible, though fallacious reasoning. In my model of a folk theory of portfolio choice, I propose that people have heard that: (i) high mean return is good; (iii) risk is bad; and (iii) diversification is good. Diversification being good might be represented by a maxim such as "Don't put all of your eggs in one basket". In order to provide a clear prediction for what people will do, I will model portfolio choice as a maximization problem, but a maximization problem using an ill-founded indirect utility function. Indeed, I intend the maximization problem to be the kind of thing a bad economist who did not know the literature might come up with to represent the three ideas: (i) high mean return is good; (ii) risk is bad; and (iii) diversification is good.

The agent is assumed to face (or to believe he or she faces) a no short-sales constraint and solves

\footnotetext{
${ }^{15}$ That is, if one is willing to depart from Bayesian updating, the reliance of an agent on a simple model $S$ need not imply that the agent will react with denial to overwhelming evidence against $S$. However, if the only way one is willing to describe an agent's reliance on the simple model $S$ is to say that the agent puts a zero prior probability on anything outside of $S$, then one is forced to predict that the agent will react with denial even to overwhelming evidence against $S$. More commonly, to avoid the implication of heedless denial, the agent is implicitly assumed to have a strictly positive prior probability on a huge range of possibilities, so that whatever the analyst thinks is the truth is sure to be included as something the agent thinks is possible.
} 


$$
\max _{\substack{s_{i} \geq 0 \\ \sum_{i} s_{i}=1}} \sum_{i}\left(\mu_{i}-\gamma \sigma_{i}^{2} / 2\right)\left(s_{i}-\theta s_{i}^{2} / 2\right)
$$

where $s_{i}$ is the share of each asset $i$ in the agent's financial portfolio, $\mu_{i}$ is the mean real return, $\gamma$ is risk aversion, $\sigma_{i}^{2}$ is the variance of the real return of asset $i$ and $\theta$ is the diversification parameter. (A plausible variant of this folk theory would use the mean and variance of the nominal return.)

There are several things worth pointing out about this folk theory. First, for this agent, the concept of diversification is not well connected to the risk considerations that better theories link it to. Indeed, tendency toward diversification has its own separate parameter, $\theta$. Some agents could have high risk aversion but no motivation towards diversification, while others have a strong motivation to diversify (but still without much understanding) corresponding to a high $\theta$. Second, other than the overall constraint that shares must add up to 1 , each asset is treated separately. The agent has no understanding of hedging. What is worse from a welfare point of view, the agent has no understanding that diversification reduces risk enough that it is relatively safe to hold a large amount of risky assets overall. The agent will be helped if some of the assets indexed by $i$ are actually mutual funds. However, in this case, the agent may "diversify" by choosing several mutual funds of the same type. Much more could be said, but this gives some idea of the kinds of "puzzles" this folk theory could help to explain. (However, I don't intend this folk theory model to be taken that seriously, but only to illustrate what I mean by a "folk theory model".)

Consider now what an agent would gain and lose by being taught a still grossly inadequate, but to economists somewhat more familiar type of indirect utility function, leading to

$$
\max _{\sum_{i} \geq 0} \sum_{i} s_{i}=1
$$

Although this second folk theory ignores all covariances between assets, it does convey the idea that diversification allows one to safely hold a relatively large amount of risky assets, because it multiplies the variances of returns by the squared shares. Indeed, this folk theory would tend to overstate this benefit of diversification, because positive covariances apply between most pairs of assets.

A third folk theory would get much closer to how economists usually think:

$$
\max _{\substack{s \geq 0 \\ \sum_{i} s=1}} s^{\prime} \mu-\gamma s^{\prime} \Omega s,
$$


where $s$ is the vector of asset shares, $\mu$ is the vector of mean returns and $\Omega$ is the variancecovariance matrix of returns. Note that even this folk theory omits many important things. For example, it omits integration of human capital into the portfolio, and the implication of this integration that many people who have small amounts of financial wealth but large amounts of human capital uncorrelated with the market should have all of their wealth in a leveraged, diversified market fund. It also omits subtle implications of an intertemporal model, such as the understanding that many of the apparent financial risks of fluctuations in the long-term real interest rate are cancelled out by the corresponding shifts in the price of purchasing a given stream of future consumption. The understanding this third folk theory brings of covariances comes at the considerable cost of either needing to understand vector and matrix notation, or being able to deal with the messy algebra that would be revealed using scalar notation.

In reality, I am confident that people's thinking about portfolio choice varies from person to person with a wild profusion of different kinds of misunderstanding. In most other contexts as well, at least where there is some complexity, any model that assumes everyone's folk theory is of the same type is likely to be false. Realizing that people do not always have the same mental model of a situation as the economist studying that situation is the first step toward facing the motley truth about people's folk theories.

\section{Conclusion}

Economic research using more and more direct data about what is in people's minds is flourishing. However, much more can be done. Fostering continued progress in this area of cognitive economics calls for three inputs. First, new theoretical tools for dealing with finite cognition need to be developed, and existing theoretical tools sharpened. Second, welfare economics needs to be toughened up for the rugged landscape revealed by peering into people's minds. Third, the statement "The data are endogenous" needs to become not only an econometrician's warning but also a motto reminding economists that new surveys can be designed and new data of many kinds can be collected to answer pressing questions.

\section{Acknowledgments}

Conversations with Robert Willis inspired this paper. I would also like to thank participants at the Japanese Economic Review conference at Keio University. This work was supported by National Institute on Aging grants P01-AG026571 and R01-AG040787 to the University of Michigan.

\section{References}

Almlund, M., Duckworth, AL., Heckman, JJ., Kautz, TD. Personality Psychology and Economics. In: Hanushek, E.Machin, S., Woessman, L., editors. Handbook of the Economics of Education. Amsterdam: Elsevier; 2011. p. 1-181.

Benjamin DJ, Heffetz O, Kimball MS, Rees-Jones A. What Do You Think Would Make You Happier? What Do You Think You Would Choose? American Economic Review. 2012; 102(5):2083-2110. [PubMed: 23275649]

Benjamin DJ, Heffetz O, Kimball MS, Rees-Jones A. Can Marginal Rates of Substitution Be Inferred From Happiness Data? Evidence from Residency Choices. American Economic Review. 2014a; 104(11):3498-3528. [PubMed: 25404759] 
Benjamin DJ, Heffetz O, Kimball MS, Szembrot N. Beyond Happiness and Satisfaction: Toward WellBeing Indices Based on Stated Preference. American Economic Review. 2014b; 104(9):2698-2735. [PubMed: 25404760]

Bourgine, P., Nadal, J-P., editors. Cognitive Economics: An Interdisciplinary Approach. Berlin: Springer-Verlag; 2004.

Conlisk J. Why Bounded Rationality? Journal of Economic Literature. 1996; 34(2):669-700.

Dekel E, Lipman B, Rustichini A. Standard State-Space Models Preclude Unawareness. Econometrica. 1998; 66:159-173.

Dietrich, F., List, C. Mentalism versus Behaviourism in Economics: A Philosophy-of-Science Perspective. 2012. [Cited April 3, 2015.] Available from URL: http://ssrn.com/abstract=2033165

Dominitz J, Manski C. Measuring and Interpreting Expectations of Equity Returns. Journal of Applied Econometrics. 2011; 26(3):352-370.

Egidi, M., Rizzello, S., editors. Cognitive Economics. Vol. I and II. Cheltenham and Northampton, MA: Elgar; 2004.

Gul, F., Pesendorfer, W. The Case for Mindless Economics. In: Caplin, A., Shorter, A., editors. The Foundations of Positive and Normative Economics. Oxford: Oxford University Press; 2008. p. $3-42$.

Herrnstein, R. The Matching Law: Papers in Psychology and Economics. Cambridge, MA: Harvard University Press; 1997.

Hudomiet P, Kezdi G, Willis R. Stock Market Crash and Expectations of American Households. Journal of Applied Econometrics. 2011; 26(3):393-415.

Ishino T, Kamesaka A, Murai T, Ogaki M. Effects of the Great East Japan Earthquake on Subjective Well-Being. Journal of Behavioral Economics and Finance. 2012; 5:269-272. (Proceedings of the 6th Annual Meeting).

Kahneman, D. Objective Happiness, Chapter 1. In: Kahneman, D.Diener, E., Schwarz, N., editors. Well-Being: The Foundations of Hedonic Psychology. New York: Russell Sage Foundation; 1999. p. 3-25.

Kimball, M. The Unavoidability of Faith, blog post, Confessions of a Supply-Side Liberal. 2013. [Cited April 3, 2015.] Available from URL: http://blog.supplysideliberal.com/post/64545705877/ the-unavoidability-of-faith

Kimball, M., Levy, H., Ohtake, F., Tsutsui, Y. Unhappiness after Hurricane Katrina, National Bureau of Economic Research Working Paper \#12062. 2006.

Kimball M, Nunn R, Silverman D. Accounting for Adaptation in the Economics of Happiness. 2015a unpublished.

Kimball M, Sahm C, Shapiro MD. Imputing Risk Tolerance from Survey Responses. Journal of the American Statistical Association. 2008; 103:1028-1038. [PubMed: 20407599]

Kimball, M., Shapiro, MD., Shumway, T., Zhang, J. Portfolio Rebalancing in General Equilibrium. University of Michigan; 2015b. working paper

Kimball, M., Smith, N. There's One Key Difference between Kids Who Excel at Math and Those Who Don't. Quartz. 2013. [Cited April 3, 2015.] Available from URL: http://qz.com/139453/theres-onekey-difference-between-kids-who-excel-at-math-and-those-who-dont/

Kimball, M., Willis, R. Utility and Happiness. University of Michigan; 2006. unpublished

Layard, R. Happiness. London: Penguin Press; 2005. This book is based to a large extent on Layard's 2003 Lionell Robbins Memorial Lectures, London School of Economics

Mankiw NG, Reis R. Sticky Information Versus Sticky Prices: A Proposal to Replace the New Keynesian Phillips Curve. Quarterly Journal of Economics. 2002; 117(4):1295-1328.

Sahm CR, Shapiro MD, Slemrod J. Check in the Mail or More in the Paycheck: Does the Effectiveness of Fiscal Stimulus Depend on How It Is Delivered? American Economic Journal: Economic Policy. 2012; 4:216-250. [PubMed: 23970951]

Shackle, GS. Expectations in Economics. Cambridge: Cambridge University Press; 1949.

Shapiro M, Slemrod J. "Consumer Response to Tax Rebates” (Revised version, October 2002). American Economic Review. 2003; 93:381-396.

Sims, C. Implications of Rational Inattention. Princeton University; 2002. unpublished paper 
Wilcox N. Review of Bourgine, P. and Nadal, J-P., eds, Cognitive Economics: An Interdisciplinary Approach. Berlin: Springer-Verlag, 2004. Journal of Economic Psychology. 2005a; 26(4):599_ 601.

Wilcox N. Review of Egidi, M. and Rizello, S., eds, Cognitive Economics (Volumes I and II). Cheltenham, UK: Elgar, 2004. Journal of Economic Psychology. 2005b; 26(5):788-792.

Woodford, M. Imperfect Common Knowledge and the Effects of Monetary Policy. In: Aghion, P.Frydman, R.Stiglitz, J., Woodford, M., editors. Knowledge, Information, and Expectations in Modern Macroeconomics: In Honor of Edmund S. Phelps. Princeton: Princeton University Press; 2002. 